\title{
IDENTIDADE TERRITORIAL GAÚCHA NO BRANDING DA CERVEJA POLAR
}

\author{
ÂNGELA FELIPPI \\ Universidade de Santa Cruz do Sul \\ Santa Cruz do Sul, Rio Grande do Sul, Brasil \\ Email: angelafe@unisc.br
}

GIOVANA GORETTI FEIJÓ DE ALMEIDA Universidade de Santa Cruz do Sul Santa Cruz do Sul, Rio Grande do Sul, Brasil Email: agenciaggoretti@gmail.com 
Resumo: $O$ artigo faz a discussão de uma identidade territorial que é hegemônica no Rio Grande do Sul, Brasil, e é utilizada no branding das marcas regionais. O foco é a análise, por meio do branding, da identidade territorial através de uma campanha publicitária da cerveja Polar, abordando as marcas nos territórios e as estratégias das transnacionais que utilizam essas identidades. Destarte, expões-se as contradições da globalização e a territorialização de capital e marcas.

Palavras-chave: identidade territorial, branding, marcas, território, desenvolvimento regional.

\section{GAUCHA TERRITORIAL IDENTITY IN BRANDING OF THE POLAR BEER}

Abstract: The article make a discussion about a territorial identity that is hegemonic in Rio Grande do Sul - Brazil - and is used in the branding of regional brands. Here, the focus is to analyze, through the perspective of branding, territorial identity through an advertising campaign Polar beer, approaching the marks in the territories and the strategies of transnational which use these identities. Thus, exposing the contradictions of globalization and territorialization of capital and brands.

Key-words: territorial identity, branding, brands, territory, regional development.

IDENTIDAD TERRITORIAL GAÚCHA EN EL BRANDING DE LA CERVEZA POLAR

Resumen: El artículo hace la discusión de una identidad territorial que es hegemónica en Río Grande del Sur, Brasil, y es utilizada en el branding de las marcas regionales. El foco es el análisis, por medio del branding, de la identidad territorial a través de una campaña publicitaria de la cerveza Polar, abordando las marcas en los territorios y las estrategias de las trasnacionales que utilizan esas identidades. Expone las contradicciones de la globalización y la territorialización de capital y marcas.

Palabras clave: identidad territorial, branding, marcas, territorio, desarrollo regional. 


\section{INTRODUÇÃO}

Cada território tem características que o diferenciam dos demais em um ou outro aspecto, portanto, não são iguais. Um território ou mesmo uma região podem ter vários elementos (construídos ou não) que lhes garante unidade, e entre eles, o cultural. Há pluralidades de culturas e identidades dentro de um mesmo território, entretanto, pode haver uma que se destaque hegemonicamente', sobressaindo-se por uma série de decisões que a caracterizam a partir de uma identidade hegemônica. É o caso do Estado do Rio Grande do Sul, que possui uma identidade territorial forte e marcante².

Os elementos identitários dos territórios têm sido integrados a estratégias mercadológicas utilizadas pelas empresas na promoção de suas marcas de produtos. Mais especificamente, as marcas regionais têm aproveitado a identidade territorial como estratégia de mercado em ações de branding para se fortaleceram e, consequentemente, seus produtos; entendendo como se dá a apropriação dessas identidades que não são inerentes a uma marca nem a um produto. São elos de identificação criados a partir do espaço vivido de um determinado território. Sendo assim, aqui se investiga o que se convencionou a chamar de identidade regional gaúcha pela perspectiva de uma identidade territorial gaúchas, e de que maneira as empresas, por meio do branding, se apropriam deste conceito e o utilizam em suas ações estratégicas na divulgação das marcas e, assim, pensá-las na perspectiva do desenvolvimento regional. $\mathrm{E}$ faz-se isso a partir da compreensão de identidade como uma construção social de cada território, enquanto espaço vivido.

Num cenário globalizado em que as regiões e os territórios têm que (re) descobrir formas de ganhar notoriedade estão as marcas regionais. Elas podem vir a ser potencializadoras estratégicas das regiões e dos territórios através da publicidade e da comunicação estratégica. $O$ artigo se debruça em uma dessas marcas regionais dentro do território do Rio Grande do Sul,

1 Segundo Stuart Hall (2001) a hegemonia diz respeito à participação e consentimento dos indivíduos em um pensamento coletivo (projeto intelectual e moral da sociedade).

2 Como já tratado em textos anteriores, entre os quais, em Felippi, 2008.

3 A identidade territorial gaúcha nasce de movimentos político-literários e da historiografia do Estado do Rio Grande do Sul - Brasil - a partir do século XIX. Está ancorada nas origens rurais pastoris do Rio Grande do Sul e no tipo humano que ocupou esse espaço. Tem como acontecimento histórico fundante a Revolução Farroupilha (1835-45). Na segunda metade do século XX, movimentos artístico-culturais e a ação do poder público consolidam essa como a construção identitária que irá marcar o Estado. 
a da cerveja Polar, que, em vez de utilizar os argumentos do próprio produto, vale-se de argumentos emocionais da identidade hegemônica gaúcha em ações estratégicas de branding para comunicar e fortalecer sua identidade enquanto marca e produto mercadológico. Salientando que este estudo de caso traz um aspecto extremamente relevante, pois a marca cerveja Polar se (re)posiciona como um produto cultural do Rio Grande do Sul e não como uma marca de cerveja que pertence a uma transnacional. Como percurso metodológico, o texto utiliza os referencias teóricos dos estudos culturais e a literatura sobre branding, trazendo uma perspectiva sob o ponto de vista do branding das peças publicitárias de uma campanha elaborada em decorrência da realização dos jogos da Copa do Mundo de 2014, em Porto Alegre-RS, problematizando as tensas relações entre o global e o regional.

\section{GLOBALIZAÇÃO, IDENTIDADE TERRITORIAL E BRANDING}

A globalização é uma forma mais avançada e também mais complexa de internacionalização4, implicando em um grau de integração funcional entre as atividades econômicas (produção, distribuição e consumo de bens e serviços) que estão organizados sob a ótica de uma estratégia mundial que está focada para um mercado global. Na história da economia havia o mercado voltado para o consumo internacional, entretanto, surge uma fusão das partes internacionais que geram o mercado mundial ou mercado global. A globalização não deixa de ser uma questão de escala e, por este motivo, tem uma estratégia diferenciada (ORTIZ,1994).

Devido à tecnicidade dos processos econômicos, as grandes empresas estão operando, cada vez mais, em escala global através de redes também globais. "As redes seriam incompreensíveis se apenas as enxergássemos a partir de suas manifestações locais ou regionais.[...]. A existência das redes é inseparável da questão do poder." (SANTOS, 2006, p. 182).

As grandes empresas utilizam os territórios conforme seus interesses econômico-políticos, baseados em seus planejamentos estratégicos. Dessa forma, as transnacionais veem os territórios e suas regiões como lugares estratégicos para a fluidez de seus produtos e mensagens e, consequentemente, a fluidez do capital econômico. Nesse sentido, muitas empresas glo-

4 Internacionalização corresponde ao aumento da extensão geográfica das atividades econômicas através das fronteiras nacionais, portanto, segundo Ortiz (1994), não é um fenômeno novo. 
bais adquirem empresas menores e, por uma questão estratégica de mercado, mantém ainda ativas as marcas que compram. A regionalização das marcas é um fator tão importante frente ao capitalismo que as corporações nacionais e globais temem perder espaço para marcas menores que têm em suas essências identitárias um forte argumento de diferenciação: sua origem geográfica associada a fortes laços entre as pessoas e suas regiões e localidades. Falar a mesma língua do consumidor local ou regional torna-se um elemento imprescindível quando o assunto são as marcas.

Território e região não se acabam devido ao processo de globalização. Negociam um diálogo entre si que nem sempre é de comum acordo. Contudo, as organizações que atuam em grande escala veem oportunidades estratégicas e valiosas nas regiões e em seus territórios. Nesse contexto surgem vários questionamentos sobre como promover processos de desenvolvimento regional dentro do global, abrindo ampla discussão sobre o global versus o regional. Ao se transpor a construção identitária das marcas atuantes em um mercado globalizado para as regiões e os territórios é importante compreender melhor conceitos-chaves sobre o assunto.

Albagli (2004) chama de territorialidade à forma como as pessoas vivem por meio de suas relações sociais e sua compreensão sobre o uso do território. O mesmo território pode ser compreendido de diferentes formas pelos seus grupos sociais e econômicos. Para Raffestin (1993), território é um espaço apropriado por atores sociais, sendo definido e delimitado por e a partir de relações de poder em suas múltiplas dimensões. Os conceitos estão interligados. O território origina-se da forma como seus atores vivem e se relacionam entre si; sejam as pessoas, grupos, empresas, enfim, todos que compartilham desse relacionamento vivido, experenciado cotidianamente. Dessa relação exposta deriva o conceito de territorialidade que cria entre seus atores a coesão social, assim como, o sentimento de pertencimento com determinado território, unindo presente, passado e futuro em uma situação dialética e que se encontra em constante movimento.

A dialética do território acaba fornecendo ao mesmo tempo significados que intensificam seu poder territorial por meio de suas identidades coletivas e regionais. É como se fosse uma contínua (re)negociação entre os atores que formam o território. Corrêa (1997) lembra que a globalização trouxe a dependência (em maior ou menor grau) de processos gerais e universais, fragmentação na divisão territorial do trabalho (especializações produtivas) e articulação dos diversos fluxos (materiais e imateriais), integrando pontos 
e áreas diversas. Originando, portanto, uma economia mundial mais complexa constituída de regiões com diversas dimensões, formas e conteúdos.

A identidade territorial utiliza todo esse aparato da comunicação-informação em formato de redes comunicacionais para manter e divulgar, interna e externamente, a representação simbólica que uma região faz uso para criar laços identitários de pertencimento entre seus atores. A identidade regional é uma construção simbólica e socialmente construída, segundo Castells (2006), por seus atores hegemônicos. Se é uma construção, ela é feita para alguém e por alguém. $O$ autor ressalta que ao estabelecer os parâmetros dessa identidade construída, se faz opções por simbologias que sustentem esse posicionamento e essas escolhas. A história e as tradições de uma região podem servir de matéria-prima para esse argumento identitário.

\section{BRANDING DAS MARCAS REGIONAIS}

Para a American Marketing Association5 (2008), "branding é fazer com que um consumidor em potencial perceba a marca como sendo a única solução para o que ele busca", ou seja, o consumidor vê a marca como a única escolha lógica para o que ela está oferecendo. Branding é um sistema de comunicação que deixa claro porque a marca importa tanto para o consumidor. Não é apenas uma escolha entre marcas concorrentes, pois não adianta ser apenas diferente. É preciso um algo a mais, uma sintonia que conquiste a atenção do público (AMA, 2008). Já a expressão "marca regional”, segundo Aaker (1996), está associada a marcas cuja atuação de suas atividades e venda de seus produtos está limitada a um espaço geográfico mais limitado, ou seja, a uma região6. Também pode estar associado a marcas que não atingiram relevância para venda de seus produtos a nível nacional ou internacional. Este estudo considera a expressão "marca territorial”, visto que, abordará as marcas que se originam de uma determinada região, utilizando argumentos também regionais em seus discursos.

Em geral, as marcas utilizam os dois tipos de atributos racionais e emocio-

5 A Associação Americana de Marketing (AMA) é uma das maiores associações de marketing do mundo. Disponível em: <http://www.marketingpower.com/_layouts/Dictionary. aspx?dLetter $=M>$.

6 Compreende-se região como sendo o conjunto de relações culturais entre um grupo e um lugar particular ou o fruto da apropriação simbólica de uma porção de espaço por um determinado grupo (CORRÊA, 1997). 
nais para ressaltarem um ou outro em suas mensagens. Os argumentos implícitos nas mensagens das marcas utilizam um discurso elaborado que traz características impregnadas de simbolismo. A construção desse simbolismo cultural é a matéria-prima utilizada pelas marcas para o desenvolvimento de suas mensagens e (re)posicionamento. $O$ território gaúcho tem crenças bem definidas e é considerado, no imaginário coletivo, como sendo um Estado que valoriza muito o que é seu. Sob esta ótica há de se considerar dois fatores.

O primeiro é a supervalorização do que é produzido no território. O segundo é desvalorização ao que vem de fora, no caso em estudo, de fora do Rio Grande do Sul. Compreender como é feita a construção da identidade da marca da Polar é buscar elementos para o entendimento da relevância da cultura e de como as mídias e as marcas se apropriam desse aspecto cultural hegemônico, além do caráter econômico que as marcas trazem para uma região. Nesse caso "o desenvolvimento deve ser visto como um processo complexo de mudanças [...] de ordem econômica, política, [...] humana e social", (OLIVEIRA, 2002, p. 40).

O sucesso de uma marca regional está ancorado em sua capacidade de reinterpretar, reinventando-se e sintonizando-se com a cultura da qual faz parte. Contudo, a marca não pode se distanciar de sua existência enquanto produto mercadológico, assim como, de sua essência identitária. É uma relação ambígua que permeia as marcas que utilizam o discurso das regiões para se manterem fortes no mercado. Segundo pesquisas da Nielsen7, até agosto de 2007, as marcas regionais eram metade do total de marcas existentes no Brasil. No ano seguinte, em pesquisa realizada entre os meses de janeiro e agosto de 2008, as marcas regionais passaram a representar $52 \%$ do total de marcas existentes no país, participantes de ações e eventos locais.

Quando uma marca age, representando de alguma maneira um determinado território, a construção de sua identidade considera primordialmente o sentimento de pertencimento a esse lugar, sua história, sua cultura, sua tradição, etc. Castells (2006, p. 23) diz que essa construção da identidade é um processo coletivo que pode partir de elementos também coletivos. Cada marca utiliza diversos elementos que buscam fortalecer sua mensagem, tor-

7 A Nielsen Company é uma empresa global de pesquisa de informações e mídia na indústria de informações de mercado e consumidor, televisão, inteligência on-line, mensuração de telefonia celular, feiras e eventos e publicações comerciais (Billboard,The Hollywood Repórter e Adweek). De controle privado, com sede em Nova York (EUA), está presente em mais de 100 países. (NIELSEN, 2013) 
nando-a clara e confiável junto aos consumidores e público-alvo. Ainda, segundo o autor, é importante saber quem constrói e para quê se constrói essa identidade, pois essas informações irão determinar o conteúdo simbólico e o seu significado para as pessoas que com elas se identificarem.

Essa construção simbólica da identidade, a qual Castells (p. 22, 2006) se refere, é um processo que se utiliza de atributos culturais locais relevantes e que irão prevalecer sobre outras fontes de significado já existentes. Nessa linha, a forma de se pensar cultura não pode ser apenas como um produto ou mercadoria. Mas como um processo que está ligado simbolicamente aos movimentos da sociedade e seus atributos culturais que se expressam na forma de ser, agir e pensar (FELIPPI, 2008). A escolha desses atributos tem relação com o que Hall (2001, p. 24) chama de construção social da identidade. Essa construção seria um sistema de representações que se ancoram em um patrimônio simbólico de um determinado grupo social. E seria esse um dos motivos que levariam um indivíduo a fazer parte de uma coletividade. Esse sistema de representações atuaria em um território determinado.

\section{MARCA GLOBAL E MARCA REGIONAL: AMBEV E POLAR}

Uma das maiores companhias cervejeiras do mundo é a Companhia de Bebidas das Américas (AmBev). Empresa de capital aberto, com sede em São Paulo, que integra a maior plataforma de produção e comercialização de cervejas do mundo: a Anheuser-Busch InBev ( $A B \operatorname{lnBev}$ ). É a cervejaria líder global e uma das cinco maiores companhias de bens de consumo do mundo. A história da AmBev nasceu em 1999, quando as centenárias cervejarias Brahma e Companhia Antarctica anunciaram a decisão de juntar esforços (AMBEV, 2014). O surgimento da companhia impulsionou o setor de bebidas brasileiro, possibilitou a entrada no mercado de novas marcas tanto da AmBev como da concorrência, ampliou o leque de produtos de qualidade a preços acessíveis, incentivou o lançamento de inovações e mais que dobrou o nível de empregos e a geração de impostos. Na época da fusão, as duas empresas empregavam 16 mil pessoas. Atualmente, a AmBev tem mais de 40 mil funcionários, dos quais aproximadamente 26 mil são do Brasil. Sua cadeia produtiva emprega, de ponta a ponta, cerca de seis milhões de pessoas. Hoje, mais de cem profissionais brasileiros ocupam cargos de liderança em todas as operações da AB InBev no mundo (Estados Unidos, 
Europa, China, Rússia) ${ }^{8}$.

Em seu portfólio, a transnacional também tem a marca da cerveja Polar, vendida em um território específico, o Rio Grande do Sul. A fábrica da Polar ficava inicialmente estabelecida no município de Estrela, Rio Grande do Sul. A empresa mudou de nome e dono ao longo das décadas - o nome Cervejaria Polar S/A foi adotado em 1969. Em 1972, a companhia foi comprada pela Antarctica. A fábrica original de Estrela já não está mais ativa, no entanto a marca segue sob o controle acionário da AmBev desde 1999. No ano de seu cinquentenário, em 1962, a empresa (ainda gaúcha) exibia comercial da cerveja marca "Casco Escuro" com os slogans: "Polar criou, a nação inteira consagrou" e "A cerveja mais cerveja do Brasil". Em 1972, a Polar S/A é adquirida pelo Grupo Antarctica Paulista e a partir desta data recebeu incentivos do município de Estrela (como doação de áreas de terras em 1973 e 1987) para manter ali sua fábrica (AMBEV, 2013).

$\mathrm{Na}$ época, empregava em torno de 800 cervejeiros. Em 1995 triplicou o lucro da Antarctica/Polar no Rio Grande do Sul9. Em 1997 aprofundou o processo de reestruturação produtiva iniciado em 1992. E em 02 de julho de 1999 eclode a notícia da megafusão das maiores cervejarias do Brasil, ou seja, Brahma e Antarctica, efetivada em 19 de abril de 2000 após aprovação do $\mathrm{CADE}^{10}$. A partir de 2001 a Antarctica/Polar encerra suas atividades, aos poucos, em Estrela/RS. Em 2004, a AmBev noticia aliança global com Interbrew ${ }^{11}$, de Bruxelas e 20 de abril de 2006, a multinacional AmBev anunciou, oficialmente, a desativação da fábrica de cervejas no município de Estrela. Contudo, a marca Polar foi mantida e permanece até hoje no mercado gaúcho (AMBEV, 2013).

8 A Ambev é a quarta maior cervejaria do mundo e líder do mercado latino-americano. Seus produtos são distribuídos em aproximadamente dois milhões de pontos de venda, metade deles no Brasil. Em seu portfólio, estão as principais marcas do mercado (Antarctica, Brahma, Bohemia, Budweiser, Quilmes e Skol). Dados disponíveis em www.ambev.com .

9 Chegando a $\mathrm{R} \$ 46.853 .000,00$ (quarenta e seis milhões oitocentos e cinquenta e três mil Reais). Neste ano, 1995, os cervejeiros receberam participação nos lucros da empresa (AMBEV, 2013).

$10 \mathrm{O}$ Conselho Administrativo de Defesa Econômica (CADE) foi criado pela lei $\mathrm{n}^{\circ}$ 4.137, em 1962, no governo do presidente João Goulart. É uma autarquia federal brasileira, vinculada ao Ministério da Justiça, que tem como objetivo orientar, fiscalizar, prevenir e apurar abusos do poder econômico, exercendo papel tutelador da prevenção e repressão do mesmo. 11 Cervejaria transnacional sediada na Bélgica. 


\section{BRANDING NAS CAMPANHAS PUBLICITÁRIAS DA POLAR}

As campanhas da Polar trazem elementos da complexa relação entre marcas, territórios e identidades e expõe a argumentação baseada na identidade hegemônica do Rio Grande do Sul, o que se dá por meio de marcadores identitários $^{12}$. De uma forma geral, as campanhas da Polar utilizam o humor e marcas da identidade gaúcha, em especial as cores oficiais (da bandeira do Estado), a comida e a bebida típicas, expressões da linguagem, costumes e datas comemorativas. Nessas marcas, impõe, sobretudo, os valores e os sentidos mobilizados pela identidade territorial hegemônica do Rio Grande do Sul.

Antes da marca Polar ser vendida para a transnacional AmBev, suas campanhas tinham foco nacional. Logo após 1999, quase não há campanhas da Polar. Somente em 2004, a Polar ressurge com o posicionamento de utilizar a identidade territorial gaúcha como estratégia principal. As mídias usadas nas campanhas publicitárias são praticamente todas na internet: site, facebook, twitter e youtube. Sazonalmente se valem da mídia impressa ou da TV, nesse caso, algumas campanhas durante ano de co-branding mais focadas na capital gaúcha, e pouquíssimas peças direcionadas para rádio. Ao fazer essa opção, acredita-se que o intuito da marca é o estimulo de uma maior interação com seus consumidores, público-alvo e simpatizantes da marca. O posicionamento atual da marca Polar é centrado no mote publicitário " $\mathrm{A}$ melhor do mundo é daqui", que se mantém praticamente igual desde 2004, apenas inserindo a palavra "mundo" a partir da campanha de 2013.

A estratégia de branding focada no mercado regional, conectada à identidade do território em que a cerveja surgiu e é comercializada, reflete-se numa abordagem tática de marketing entre a marca endossante, a AmBev e uma das marcas de seu portfólio, a Polar; tanto nas embalagens do produto, quando nas publicidades. Inclusive, o slogan insiste no oposto. Ao dizer que "A meIhor do mundo é daqui", tendo o elemento "mundo" na promessa de valor da marca, ficam subentendido dois argumentos: 1) a questão da superioridade dos produtos dos gaúchos, reforçando esse sentido presente na identidade hegemônica do Rio Grande do Sul e, 2) sendo a AmBev uma das maiores cervejarias do mundo, não deixa de a palavra "mundo" fazer referência à marca

12 Marcadores identitários são símbolos indicativos de uma determinada construção identitária. Entre os principais símbolos da identidade territorial gaúcha estão bandeira, hino, cores, pássaro, planta, vestimenta oficiais; datas comemorativas; linguajar; comida e bebida típicas; costumes e valores, entre outros difíceis de esgotar. 
endossante, mas de forma mais sutil, sem ir de encontro com a marca regional. As duas marcas convivem numa tensão global-local de comum acordo entre si, fluindo em um território que tem uma identidade muito específica e fortalecida. Tudo é criado, planejado, articulado para o consumo contínuo das marcas. E se há um declínio em sua linha de vida, o posicionamento adotado pela marca é refeito, podendo, inclusive criar uma nova identidade para a mesma, indicando a função da publicidade no capitalismo globalizado.

Posto a forma de operação publicitária da Polar e constatada a relação da estratégia da marca com a identidade territorial gaúcha adotada desde 2004, para o artigo optou-se por analisar a campanha publicitária relacionada à realização de jogos da Copa do Mundo, em Porto Alegre/RS, em 2014. A campanha "Latas hospitaleiras" divulga o lançamento de oito novas latas da cerveja Polar com referência aos países das equipes de futebol que jogam em Porto Alegre-RS, usando o idioma e as cores da bandeira dos países em latas individuais. São tomados dois anúncios veiculados na fanpage da Polar no facebook'13 (Figura 1 e Figura 2). Analisam-se aspectos (1) verbais e (2) não verbais dos anúncios sob três fatores que compõem o branding: (a) identidade da marca; (b) (re)posicionamento; (c) comunicação. Neles, observa-se a construção de argumentos físicos, emocionais, simbólicos e culturais.

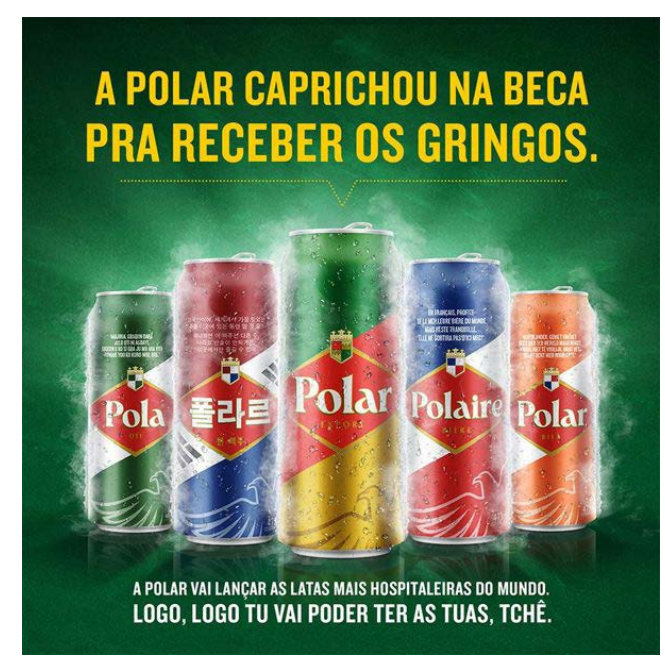

Figura1. Fonte: https://www.facebook.com/CevaPolar/ photos/a.185742364828716.42487.158120304257589/579208858815396/?type=1\&theater

13 Até o fechamento do artigo, em abril de 2014, a campanha havia divulgado somente os dois anúncios no facebook, que, imagina-se, tiveram a função de pré-teste da campanha, disponíveis em https://www.facebook.com/ CevaPolar/photos/a.185742364828716.42487.158120304257589/579208858815396/?type=1\&theater e Disponível em <https://www.facebook.com/CevaPolar/photos |a.185742364828716.42487.158120304257589/579208858815396/:type=1\&relevant_count=1> 

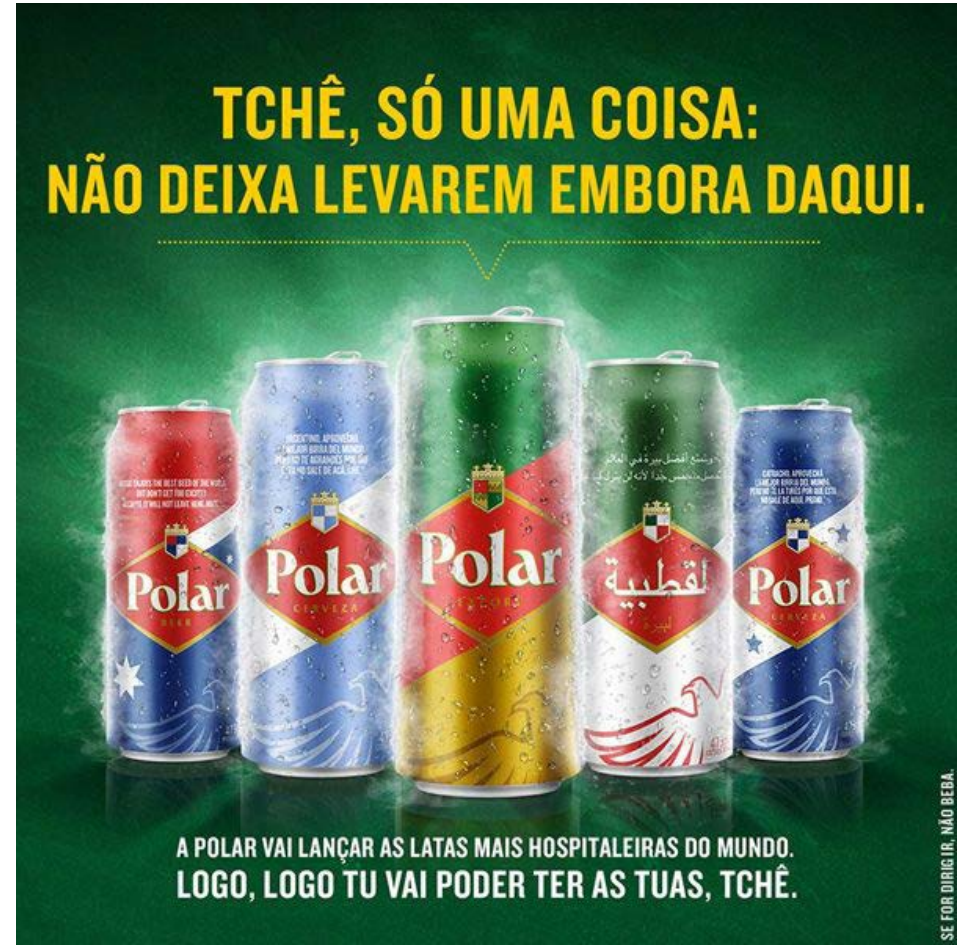

Figura 2. Fonte: https://www.facebook.com/CevaPolar/photos /a.185742364828716.42487.158120304257589/579208858815396/?type=1\&relevant_count=1

Em relação ao conteúdo verbal, as anúncios têm o seguinte texto: " $\mathrm{A}$ Polar caprichou na beca para receber os gringos" (Figura 1), "Tchê, só uma coisa, não deixa levarem embora daqui" (Figura 2) e "A Polar vai lançar as latas mais hospitaleiras do mundo. Logo, tu vais poder ter as tuas, tchê." (Figuras 1 e 2). Em cada lata, cuja foto está nos anúncios (Figuras 1 e 2), na língua de cada um dos países que jogam o mundial no Estado, o texto que aparece é: "Aproveita a melhor ceva do mundo, mas não te agiganta que ela não sai daqui, tchê." Deste modo, o conteúdo do anúncio apela para os consumidores gaúchos, o que pertence, o que teria direito, de fato, à cerveja Polar e, inclusive, às "latas hospitaleiras", muito embora, aparentemente, sejam feitas para o estrangeiro. Enquanto que o conteúdo verbal das latas, aparentemente, se destina ao estrangeiro, o que não pertence, o "outro" na relação de identidade.

Há coerência entre anúncios e mídia adotada, pois, como o nome sugere, está numa fanpage, num espaço do público fidelizado que, apesar da abrangência da internet, trata-se de uma página regional/nacional pela língua e pelos argumentos simbólicos e culturais usados no conteúdo. Assim, o consumidor aparentemente visado com a campanha das latas hospitaleiras não acessaria a fanpage, ao menos até tomar conhecimento das latas e 
da cerveja. Então, os anúncios parecem serem dirigidos ao território de circulação da Polar, serem um informe ao público tradicional da ação da marca Polar, o que pode querer gerar sentidos de consideração por este público, como fazer uma sondagem (pré-teste da campanha) sobre sua reação a estratégia ainda não colocada no mercado de fato. O branding da Polar mantém, com isso, a relação com o território e com o argumento da marca baseado na identidade territorial gaúcha e com o (re)posicionamento adotado na última década.

No caso do produto lançado pelos anúncios, as "latas hospitaleiras", há outro movimento. A identidade da marca se altera, em parte, incorporando idioma e cores oficiais dos países contemplados pela campanha, mantendo a identidade visual da marca no verso da lata, que repete a identidade visual tradicional, como se vê na lata ao centro das fotos dos anúncios (Figuras 1 e 2). Entretanto, no que seria a parte frontal da embalagem do produto (lata de cerveja da Polar), a identidade visual se altera significativamente em seu layout, mudando cores e nome da cerveja (traduzido para o país visitante). O símbolo da marca mantém-se em formas e localização, sendo as mudanças maiores nas cores da marca (usando as cores dos países) e na tradução do nome da marca na própria embalagem, que em alguns casos muda drasticamente, como no caso de Nigéria, Holanda, França, Coréia e Argélia. De oitos latas alusivas à copa do mundo 2014, apenas três utilizam o nome da marca em sua totalidade. A saber: Honduras, Austrália e Argentina.

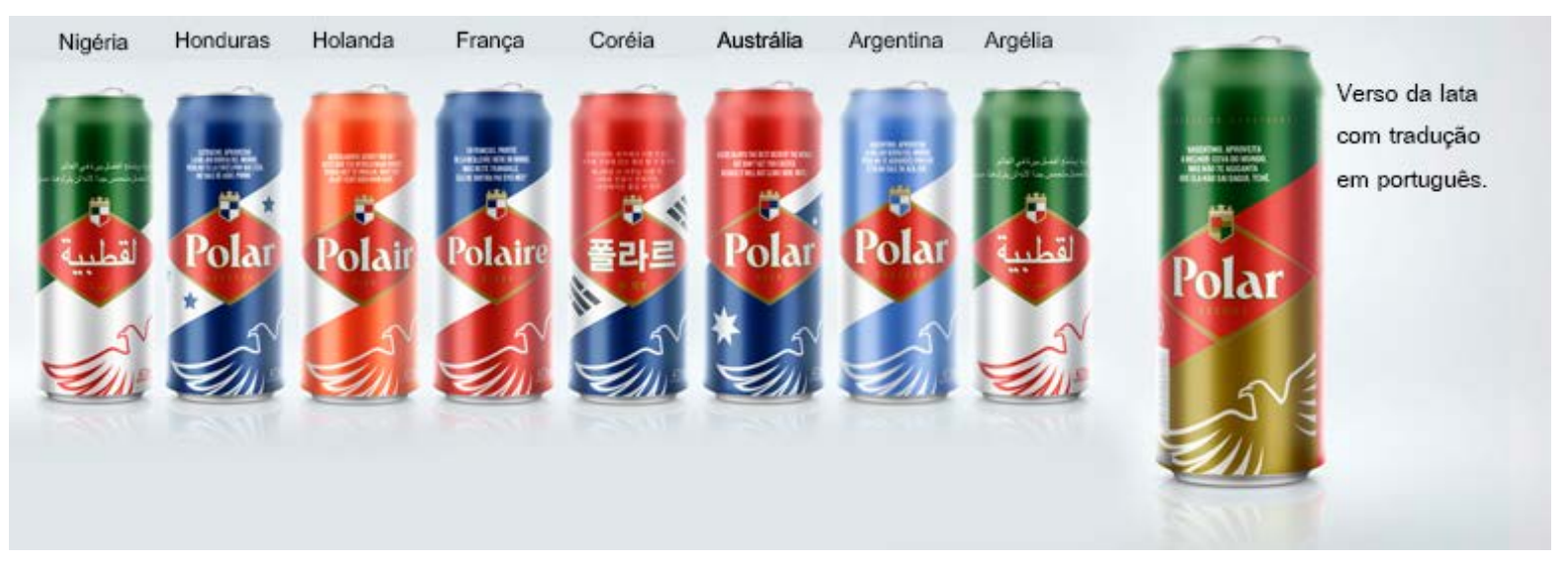

Figura 3. Fonte: Montagem das autoras com base na imagem das latas dispostas em <https://www. behance.net/gallery/LATAS-COPA-2014/14069079>.

Observando os argumentos (físicos, emocionais, simbólicos e culturais), a campanha mantém o aspecto emocional. E mantém em parte os dois últimos, quando se dirige aos consumidores tradicionais. Inova nos apelos 
simbólicos e culturais dirigidos ao público sazonal, o estrangeiro, quando aciona cores oficiais e idioma, alterando parcialmente a identidade da marca e significativamente a identidade visual do produto (embalagem da lata).

Pelo exposto acima, tem-se uma estratégia interessante e arriscada, de manter o argumento na identidade do território de circulação do produto, e, ao mesmo tempo, buscar conquistar o "outro", apelando para outras identidades, as nacionais. Em que pese a estratégia ser aprovada ou não pelo consumidor, o que ela denuncia é a tensão entre o regional e o global, entre o que a globalização provoca nos territórios. A estratégia montada para atender ao evento Copa do Mundo, no território em que circula a cerveja, gera um desvelamento da ação das empresas transnacionais nos territórios. Ou seja, o vínculo que o branding mantém com território é, mais do que laços efetivamente estabelecidos, um posicionamento, uma estratégia de mercado, pois ao surgir uma nova situação de mercado, a estratégia tenta se adequar à mesma, tendo que mexer com o que vinha sendo sustentado até então.

Desnuda-se o fato de a Polar não ser mais, de fato, do território, ter laços estabelecidos pela origem regional e pela história construída como marca e como produto junto à população. Ao travestir suas latas com as marcas de identidades nacionais distintas, mesmo usando o argumento da hospitalidade, uma marca da identidade gaúcha, revela-se o caráter provisório e estratégico das identidades de marca e as formas de operação do capital global pelo planeta. As contradições presentes nas marcas regionais adquiridas pelo capital global se fazem aparecer em momentos como o da campanha das "latas hospitaleiras", que tem como contexto a Copa do Mundo de 2014, evento mundial que tem gerado uma série de reações em boa parte do território nacional, tanto críticas à forma como o capital mundial e suas organizações agem no território, como de tentativa de tradução do evento em oportunidades de negócios para as marcas regionais, nacionais e transnacionais que operam no referido território, como é o caso da Polar.

\section{CONSIDERAÇÕES FINAIS}

Mostra-se relevante considerar a abordagem das questões simbólicas a partir de uma perspectiva sociocultural como o feito aqui. Firma-se posição sobre ser necessário problematizar a relação entre global e regional tentando compreender a força e a influência que uma cultura tem, as intersecções do global nessa cultura e também na própria construção das marcas que va- 
lorizam seus territórios através de suas identidades regionais. O que parece é que as marcas se tornaram tão comoditizadas que se fez essencial ir além de seus atributos emocionais e físicos. O que leva a uma discussão maior sobre que força seria essa que os territórios conferem às marcas regionais fazendo com que produtos mercadológicos passem a ser também produtos culturais. E vale o contrário. Pensar a forma que as marcas regionais podem dar força aos territórios e suas identidades através de suas campanhas publicitárias. Marcas que se apoiam em territórios ou territórios que se apoiam em marcas são perspectivas diferentes a serem consideradas. Essa opção estratégica das empresas, principalmente das que perderam a relação de origem com os lugares, como é o caso das transnacionais, por exemplo, leva ao questionamento do que seria uma marca regional realmente e em que ela se diferencia das marcas mercadológicas.

O que se percebe quando o assunto é branding é que há uma relação muito forte com a multidisciplinaridade, ou seja, as ações estratégias na gestão de uma marca estão também atreladas, além das questões do mercado, às ciências sociais e humanas (comunicação, sociologia, antropologia, psicologia, semiótica, marketing e outras). Esse conjunto de abordagens se torna, portanto, indispensável para a elaboração de eficientes estratégias de branding. Construir marcas fortes em um espaço globalizado como se tem hoje, é uma tarefa que exige pensar, planejar, articular e atuar global e localmente.

Refletir como todos esses conceitos se relacionam entre si é uma oportunidade para marcas virem a investir mais nos territórios; promovendo assim, um maior desenvolvimento regional onde todos os atores, sociais e econômicos, estejam envolvidos e integrados. Ressalta-se que quando se trata de desenvolvimento regional é importante ter em mente as questões relativas ao global versus o regional. Quanto mais tensa essa relação, mais enfraquecida se torna a presença das marcas regionais, no caso, a Polar, que sucumbe ao ser incorporada por uma empresa transnacional, a AmBev. No entanto, essa mesma companhia global se apresenta, em suas campanhas publicitárias, como marca regional e não global.

\section{REFERÊNCIAS}

AAKER, D.. Criando e administrando marcas de sucesso. São Paulo: Futura, 1996.

ALBAGLI, S.. Território e Territorialidade. In LAGES, V.; BRAGA, C.; MORELI, G. (Org.). Territórios em movimento: cultura e identidade como estratégia de inserção competitiva. Rio de Janeiro : Relume Dumará, 2004, p. 24-65. 
AMBEV. Site institucional desenvolvido para a cervejaria AmBev, 2013. Disponível em: <AmBev.com.br>. Acesso em: 23 set. 2013.

AMERICAN MARKETING ASSOCIATION. AMA Dictionary. Chicago, 2008. Disponível em: <http://www.marketingpower.com/_layouts/Dictionary.aspx?dLetter=

M>. Acesso em: 10 ago. 2013.

CASTELLS, M.. O poder da identidade. São Paulo: Paz e Terra, 2006.

CEVA POLAR. Fanpage oficial da marca desenvolvido pela Paim Comunicação, 2010. Disponível em: <AmBev.com.br>. Acesso em: 23 set. 2013.

CORRÊA, R. L.. Região. A tradição geográfica. In: CORRÊA, R. L.. Trajetórias Geográficas. Rio de Janeiro: Bertrand Brasil, 1997, p. 183-196.

DECARLI, R.. Latas da Polar: Copa 2014. Porto Alegre, 27 jan. 2014. Disponível em <https:// www.behance.net/gallery/LATAS-COPA-2014/14069079>. Acesso em: 05 fev. 2014.

FELIPPI, Â. C. T.. Jornalismo e identidade cultural: construção da identidade gaúcha em Zero Hora. Santa Cruz do Sul: EDUNISC, 2008. Disponível em http://www.unisc.br/portal/ pt/editora/e-books/61/jornalismo-e-identidade-cultural- trucao-da-identidade-gaucha-emzero-hora.html.

FLORES, M.. A identidade cultural do território como base de estratégias de desenvolvimento: uma visão do estado da arte. 2006. Disponível em <http://indicadores.fecam.org. br/uploads/28/arquivos/4069_FLORES_M_Identidade_Territorial_como_Base_as_Estrategias_Desenvolvimento.pdf $>$ Acesso 17 set 2013, às 15h20min.

HALL, S.. A identidade cultural na pós-modernidade. Rio de Janeiro: DP\&A, 2001.

NIELSEN. Site Institutional desenvolvido para The Nielsen Company. Disponível em < http://acnielsen.com.br/press/MarcasRegionais.shtml>. Acesso em: 12 nov. 2013.

OLIVEIRA, G. B.. Uma discussão sobre o conceito de desenvolvimento. Revista FAE, Curitiba, v.5, n.2, p.37-48, maio-ago. 2002.

OLIVEN, R.. A dupla desterritorialização da cultura gaúcha. In FONSECA, C. (org). Fronteiras da Cultura. Porto Alegre: UFRGS, 1993. p 24-40.

ORTIZ, R.. Mundialização e cultura. São Paulo: Brasiliense, 1994.

RAFFESTIN, C.. Por uma geografia do poder. São Paulo: Ática, 1993.

SANTOS, M.. A natureza do espaço: técnica e tempo, razão e emoção. São Paulo: Hucitec, 1996. 


\section{Ângela Felippi}

Jornalista, doutora em Comunicação Social pela PUCRS, professora pesquisadora do Programa de Pós-Graduação em Desenvolvimento Regional e do Departamento de Comunicação Social da Universidade de Santa Cruz do Sul, RS.

Email: angelafe@unisc.br

\section{Giovana Goretti Feijó de Almeida}

Publicitária, especialista em Gestão de Marcas e mestranda em Desenvolvimento Regional pela Universidade de Santa Cruz do Sul, RS. Tem experiência nas áreas de Marketing, Merchandising, Planejamento Estratégico e Criação Publicitária. Email: agenciaggoretti@gmail.com 